\title{
How to Promote Purple Martins in North Florida ${ }^{1}$
}

\author{
Holly K. Ober ${ }^{2}$
}

Purple Martins (Progne subis) are the largest species in the swallow family in the United States (Figure 1). They are highly social, cavity-nesting birds.

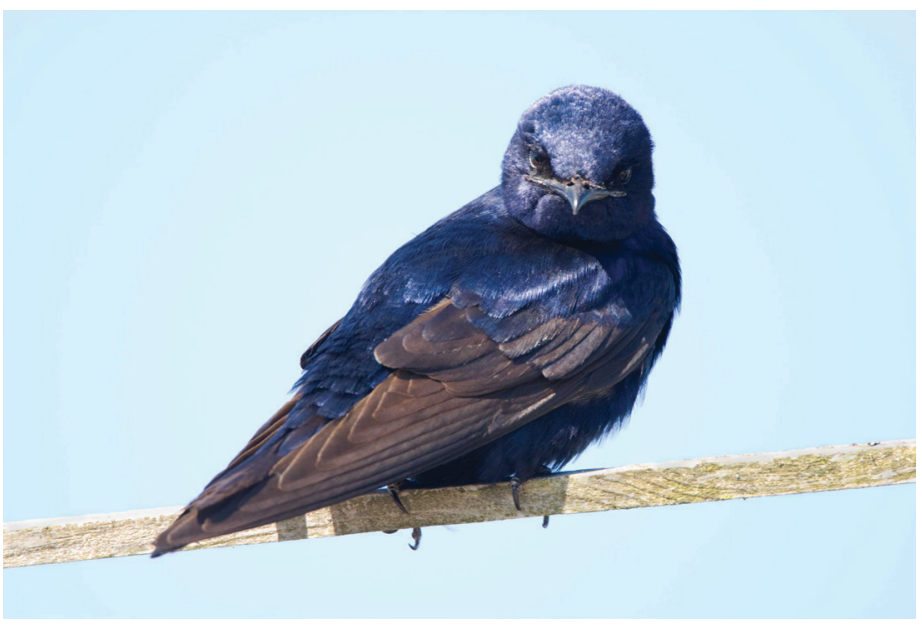

Figure 1. An adult male purple martin (Progne subis).

Credits: Birdlmages/iStock/Getty Images Plus

In the eastern United States, martins are completely dependent on human-made housing due to shortages of natural options. Martins will nest in houses with many compartments or in groups of gourds mounted close together (Figure 2). It can take time to attract martins to a new area, so if you're starting a new colony, you may want to begin by providing a small number of housing compartments and add more as your colony expands. Colonies become more stable as the number of martins increases.

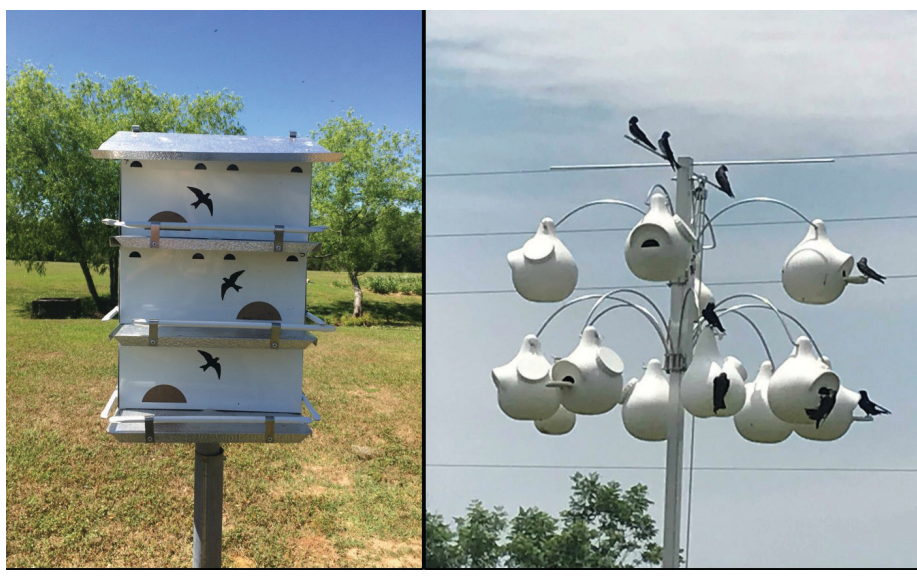

Figure 2. Purple martins are colony-nesting birds that thrive when housing options allow many individuals to roost in close proximity. Credits: Holly Ober, UF/IFAS

Purple martins select nest sites in open, grassy areas that lack tall trees. They also like to nest in areas with human activity. It's best to place your houses or gourd racks in a field or large, open yard at least 30 feet from tall trees or buildings (Figure 3 ). Be sure that the houses are at least 12 feet off the ground and that there are no trees taller than the nest compartments nearby. A predator guard can prevent snakes or raccoons from gaining access to nests. A telescoping pole, pulley system, or pivoting pole is helpful for accessing nest cavities to clean them at the end of each nesting season. It will also allow you to monitor nesting activity periodically to check for problems.

1. This document is WEC405, one of a series of the Department of Wildlife Ecology and Conservation, UF/IFAS Extension. Original publication date March 2019. Visit the EDIS website at https://edis.ifas.ufl.edu for the currently supported version of this publication.

2. Holly K. Ober, associate professor and Extension specialist, Department of Wildlife Ecology and Conservation, UF/IFAS North Florida Research and Education Center, Quincy, FL 32351. 


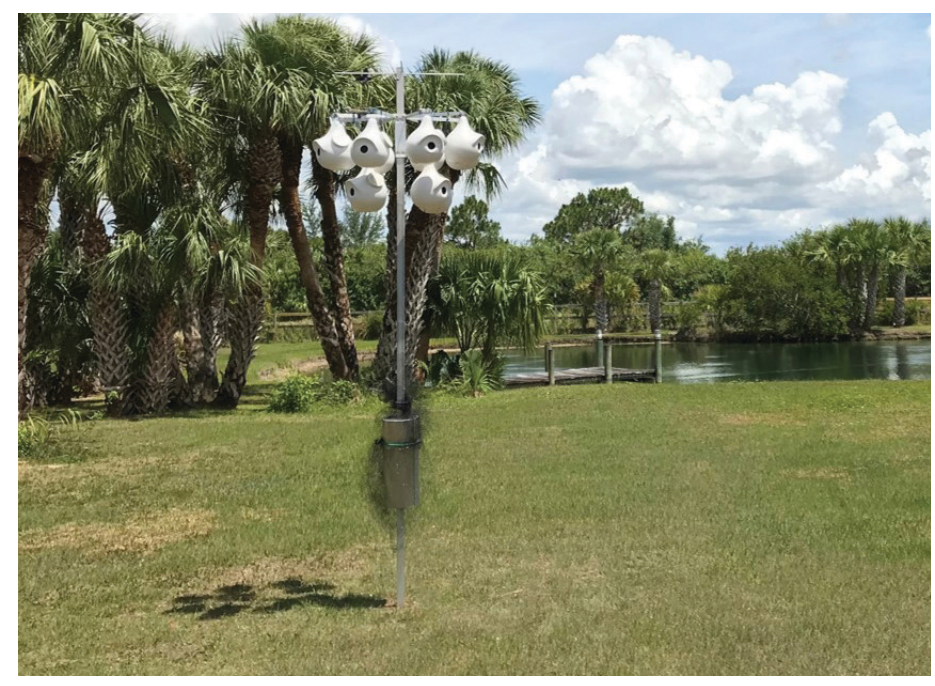

Figure 3. Purple martin housing should be located in open, grassy areas with no tall trees and should be mounted with a system that enables housing to be lowered for nest checks and maintenance. Credits: Pam Winegar

Purple martins live in South America part of the year and then migrate to North America during the winter or spring to nest. Martins appear in north Florida in late January or early February each year. They depart the region after they finish nesting, which is in late June or July. Non-native birds that don't belong in Florida (house sparrows, Passer domesticus, and European starlings, Sturnus vulgaris) can compete for nesting sites. To keep your nest cavities available for martins, consider making them unavailable when martins are not in the region (between July and January each year). You can accomplish this by either removing houses or gourds from their poles or closing cavity entrances.

Several clues could alert you if some other species of bird builds a nest in the cavities you intended for martins. First, adult martins should be visible because they enter and exit nests frequently throughout the day. Second, martins have distinctive nests. In fact, they don't construct true nests. They simply collect leaves, sticks, grass, and sometimes mud, and place these items loosely in the nest chamber (Figure 4). Females lay one white egg per day over the course of several days, and each nest typically has 2-7 eggs total. Females then incubate the eggs for 2-3 weeks. The eggs hatch over the course of $2-3$ days. Both parents then feed the chicks, which gain feathers and begin to fly 4 weeks after hatching.

Purple martins return to the same nesting location each year. Therefore, it's important to provide suitable housing, or birds will move elsewhere the next time they migrate to Florida. Over the course of a 6-year period, we tested seven commercially available housing options to determine what is best for martins in North Florida: small plastic gourds, large plastic gourds with round entrances, large plastic gourds with crescent-shaped entrances, large plastic gourds with porches, large natural gourds, 6-chamber polypropylene houses, and 6-chamber aluminum houses (Figure 5). Small plastic gourds were approximately seven inches in diameter, whereas large plastic and natural gourds were about ten inches in diameter. We adjusted internal walls of both types of houses so that they each offered six- by 12 -inch compartments. All total, birds had 36 cavities to choose from.

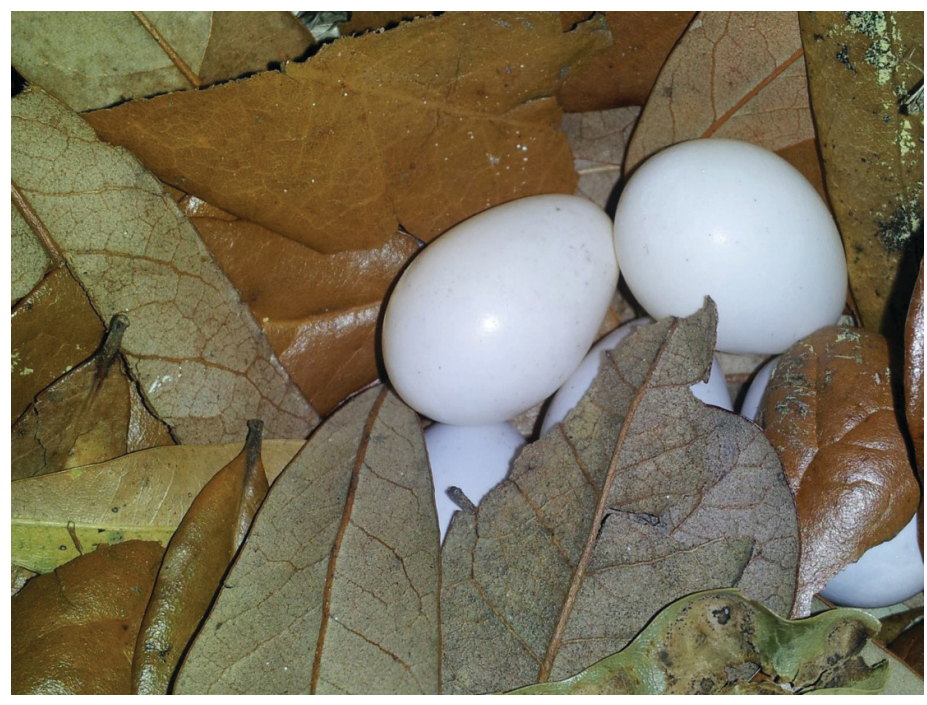

Figure 4. Purple martins don't create true nests. Rather, they line nest chambers with leaves, sticks, and grass before laying eggs.

Credits: Holly Ober, UF/IFAS

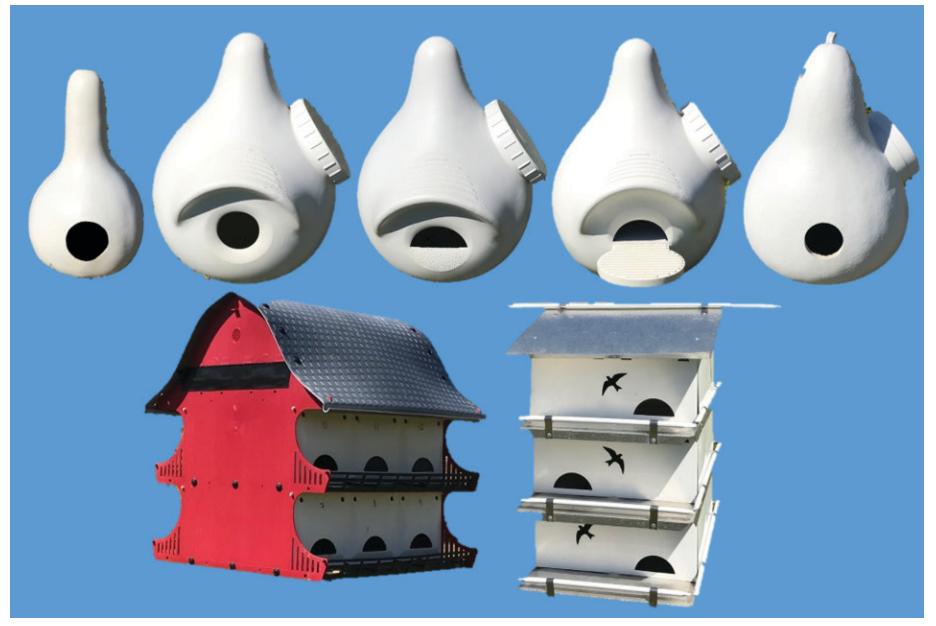

Figure 5. Purple martin housing tested in north Florida. From top to bottom and left to right: small plastic gourd, large plastic gourd with round entrance, large plastic gourd with crescent-shaped entrance, large plastic gourd with porch, large natural gourd, 6-chamber polypropylene house, and 6-chamber aluminum house.

We found that martins had similar preferences for both types of houses (aluminum and polypropylene), and for all large gourds (regardless of entrance shape, the presence of a balcony, and whether made of plastic or natural). The only 
option that martins regularly avoided building nests in was small gourds: very few birds used these.

We found that martins fledged the greatest numbers of chicks in natural gourds and large gourds with porches, followed closely by aluminum or polypropylene houses (an average of 2.5 to 3 chicks per nest chamber), and large gourds with round or crescent-shaped entrances (an average of 2 chicks per nest chamber). Birds very rarely produced any chicks in small gourds.

\section{Recommendations}

1. Choose housing with appropriate characteristics

- Nest chamber size: Gourds or houses should have compartments larger than 36 square inches (i.e., gourds should be larger than seven inches in diameter and house chambers should be larger than six inches by six inches). Our research shows that martins rarely select small gourds; when they do use them, very few of their chicks survive. Some commercially available houses have the option to remove walls to enlarge chambers. This additional space is advantageous because it can keep nestlings cooler during hot weather, and reduce the ability of predators (owls) to access chicks through the entrance.

- Rain: An overhang above each entrance can prevent rain from wetting nests. Holes in the floor can allow rainwater that enters to flow out the bottom. Consider caulking plastic gourds along their seams if they're the type made of two pieces of plastic. The caulking will prevent water from entering at the joints.

- Entrance hole: Round entrances should be approximately two inches in diameter and located an inch to an inch and a half above the floor. Use crescent-shaped entrances to keep out starlings in areas where they compete with purple martins for nesting spots. Crescent-shaped entrances should be slightly larger in diameter than round entrances.

- Access: It's much easier to monitor nesting activity and clean nest cavities when there's an access port large enough to fit a human hand on a gourd, or a hinged door on a house.

- Wind: Mount gourds so they can swing but not twist in the wind and far enough apart that they will not bump one another; mount houses on a sturdy pole that doesn't sway excessively.

- Color: A white exterior will reflect sunlight and help maintain cool temperatures.
- Number: Colonies given very few nest compartments will be unstable; it's best to gradually add new nesting options as your colony grows.

\section{Choose appropriate locations}

- Locate the gourd rack or house in an open, grassy area (lawn or field), so birds have plenty of flight space when entering and exiting nests.

- Locate gourd racks or houses at least 30 feet from the nearest tree, and in locations that have no trees taller than the house nearby.

- Locate gourd racks or houses near a building or other areas of human activity.

- Gourd racks or houses can be located near telephone or electric wires; these will be used by perching birds.

- Make sure the lowest gourds or house compartments are 12-20 feet above the ground.

\section{Prevent predator access}

- A stovepipe-style guard can prevent snakes, raccoons, and opossums from climbing a pole.

- Metal bars can prevent owls from reaching into entrance holes to steal chicks.

\section{Provide regular maintenance}

- Mount the gourds or house on a telescoping pole, with a pulley system, or with a pivoting pole, or mount them low enough that a ladder will allow access, so that maintenance is possible each year when birds migrate away.

- Remove old nest material before each new nesting season (by mid-January) to remove parasites.

- Consider taking gourds or houses down August-January to reduce weathering and to prevent use by other bird species that could compete with martins.

- Wash used gourds and houses with soap and water and/ or $10 \%$ bleach solution before each new nesting season to remove parasites.

- Return the gourds or house to the same height and orientation every year.

- Check nests once a week to keep track of nesting and hatching so you know if predators are cause for concern.

5. Experiment to assess the preferences of birds in your area

- If you have space, put up several styles of gourds (plastic, natural) and several houses (aluminum, plastic) to 
determine which the birds prefer, and from which they fledge the greatest number of chicks.

- Our experiments show that small gourds do not work well; martins produce more chicks in houses (aluminum or polypropylene, with six-inch by 12 -inch chambers), and large gourds (natural or plastic, with approximately 10-inch diameters).

\section{Additional Information}

- Cornell Lab of Ornithology: https://www.allaboutbirds. org/guide/Purple_Martin/overview

- Audubon Society: https://www.audubon.org/field-guide/ bird/purple-martin

- Purple Martin Conservation Association: https://www. purplemartin.org/ 